\title{
Mandatory and recommended vaccination in the EU, Iceland and Norway: results of the VENICE 2010 survey on the ways of implementing national vaccination programmes
} \author{
VENICE project gatekeepers and contact points ${ }^{5}$ \\ 1. Radboud University, Nijmegen, Nijmegen, the Netherlands \\ 2. Istituto Superiore di Sanitá, Rome, Italy \\ 3. European Centre for Disease Prevention and Control, Stockholm, Sweden \\ 4. University of Bari “Aldo Moro", Bari, Italy \\ 5. The members of the group are listed at the end of the article
}

M Haverkate ${ }^{1}$, F D’Ancona (dancona@iss.it) ${ }^{2}$, C Giambi $^{2}$, K Johansen³, P L Lopalco ${ }^{3}, \mathrm{~V}$ Cozza $^{4}$, E Appelgren ${ }^{2}$, on behalf of the

Haverkate M, D'Ancona F, Giambi C, Johansen K, Lopalco PL, Cozza V, Appelgren E, on behalf of the VENICE project gatekeepers and contact points. Mandatory and recommended vaccination in the EU, Iceland and Norway: results of the VENICE 2010 survey on the ways of implementing national vaccination programmes. Euro Surveill. 2012;17(22):pii=20183. Available online: http://www.eurosurveillance.org/ViewArticle.aspx?Articleld=20183

This report provides an updated overview of recommended and mandatory vaccinations in the European Union (EU), Iceland and Norway, considering the differences in vaccine programme implementation between countries. In 2010, the Vaccine European New Integrated Collaboration Effort (VENICE) network, conducted a survey among the VENICE project gatekeepers to learn more about how national vaccination programmes are implemented, whether recommended or mandatory. Information was collected from all 27 EU Member States, Iceland and Norway. In total 16* countries do not have any mandatory vaccinations; the remaining $13^{*}$ have at least one mandatory vaccination included in their programme. Vaccination against polio is mandatory for both children and adults in 11* countries; diphtheria and tetanus vaccination in $10^{*}$ countries and hepatitis B vaccination in 9* countries. For eight of the 15 vaccines considered, some countries have a mixed strategy of recommended and mandatory vaccinations. Mandatory vaccination may be considered as a way of improving compliance to vaccination programmes. However, compliance with many programmes in Europe is high, using only recommendations. More information about the diversity in vaccine offer at European level may help countries to adapt vaccination strategies based on the experience of other countries. However, any proposal on vaccine strategies should be developed taking into consideration the local context habits.

\section{Introduction}

Vaccinations are one of the most important tools of primary prevention. All countries in the European Union (EU) have a long tradition of implementing vaccination programmes. The level of control over diphtheria, Haemophilus influenzae type b (Hib) infections, hepatitis $B$, polio and tetanus is excellent in many countries [1].
The burden of measles, mumps, rubella, and pertussis decreased dramatically over the last decades, but there is still room for improvement in those programmes in many EU countries [2]. Strong efforts are being made to accelerate the implementation of newly introduced vaccines against pneumococcal, meningococcal and human papillomavirus disease.

In the presence of such a large variety of vaccines on offer, the way vaccination programmes are organised differs considerably between countries. The vaccines included in the programme, the type of vaccine used, the total number of doses administered, and the timing of the vaccinations vary. Vaccines can also be offered in many different ways: usually, the vaccines included in the routine (childhood) vaccination programme are paid for by the national healthcare system, whereas in some countries other vaccines need to be paid for up front by the recipient [3]. There are also large differences in whether vaccinations included in the national programmes are recommended or mandatory. Mandatory vaccination can be enforced by legislation, even though the term 'mandatory' has to be interpreted differently in different countries.

The Vaccine European New Integrated Collaboration Effort (VENICE) is a European network of experts working in the field of immunisation. All 27 EU Member States plus Iceland and Norway participate in VENICE. In each country a so called gatekeeper for VENICE is identified among the national experts in vaccinepreventable diseases [4]. In 2007, VENICE conducted a survey on immunisation programmes. The survey also included some questions whether vaccinations were recommended or mandatory. Of the 28 participating countries, 10 reported mandatory vaccinations for 
different vaccines in their national immunisation programmes [3].

In the meantime, vaccination programmes have changed. New vaccines have been added to the immunisation programmes [5] and legislation about recommended and mandatory vaccinations may have changed. Therefore, the aim of this article is to provide an updated overview of recommended and mandatory vaccinations in the EU countries, Iceland and Norway, considering the differences in the modality of vaccine programme implementation between countries.

\section{Methods}

The national VENICE gatekeepers from the participating countries, the $27 \mathrm{EU}$ countries plus Iceland and Norway, were sent a survey by email and asked to fill it out. The survey addressed the question whether the different childhood vaccinations were recommended (i.e. voluntary) or mandatory. A definition of 'recommended' and 'mandatory' was provided in order to avoid misinterpretation. The following definitions were used:

- Recommended: vaccination included in the national immunisation programme for all or some specific groups independent of being funded or not.

- Mandatory: a vaccination that every child must receive by law without the possibility for the parent to choose to accept the uptake or not, independent of whether a legal or economical implication exists for the refusal.

The gatekeepers were asked to provide information about childhood vaccinations against: diphtheria, Hib, hepatitis A, hepatitis B, human papillomavirus (HPV), influenza, invasive disease caused by Neisseria meningitidis serogroup C, invasive pneumococcal disease, measles-mumps-rubella, (MMR), pertussis, polio, rotavirus, tetanus, tuberculosis (with Bacillus CalmetteGuérin, BCG) and varicella. The reply options were (i) recommended (for all or for people at risk), (ii) mandatory (for all or for people at risk), or (iii) absence of recommendation. Data were collected in November 2010. Data from all countries were sent to the VENICE gatekeepers who were asked to validate them in April 2011.

\section{Results}

In total 28 of the 29 participating countries responded to the survey. For four countries (Estonia, Germany, Luxembourg and the Netherlands) additional information was found on the websites of the respective national public health institutes, which allowed the table for all 29 countries to be completed [6-10]. Data were validated from 19 countries. The results per country can be found in table 1 .

The results according to vaccine are shown in Table 2.

All 29 countries include vaccination against diphtheria, hepatitis $B$, Hib, influenza, MMR, pertussis, polio and tetanus in their programme. In total 28 countries include vaccination against invasive pneumococcal disease in their recommendation or legislation, some countries only for children and others also for adults or risk groups. Most other vaccinations (against hepatitis A, HPV, invasive disease caused by Neisseria meningitidis serogroup C, tuberculosis (with BCG) and varicella) are considered by at least 20 of the participating countries. An exception is observed for rotavirus vaccination, which is only included in the national immunisation programme for nine of the 29 countries.

In total $16^{*}$ countries do not have any mandatory vaccinations; the remaining $13^{\star}$ countries have at least one mandatory vaccination included in their programme. Vaccination against polio is mandatory for all children in $11^{\star}$ countries; diphtheria and tetanus vaccination is mandatory in $10^{*}$ countries, and hepatitis $B$ vaccination in $9^{*}$ countries. For eight of the 15 vaccines considered here, some countries have a mixed strategy of recommended and mandatory vaccinations. Usually this means that the vaccination is recommended for the whole population, but that it is mandatory for some risk groups.

\section{Discussion}

Mandatory vaccination may be considered as a way of improving the compliance to vaccination programmes. However, many programmes in Europe are effective even though voluntary, just with recommendations.

In the vaccination field, legal consequences can be very different: they can be very strong - including pecuniary penalties, difficulty to attend public schools, or even penal consequences for the parents - or can be much milder with the possibility of choosing to 'optout'. Moreover, the enforcement varies in practice. It is possible that in some cases penalties are only theoretical and never applied. This information was not collected in this survey because it is difficult to evaluate the national context and differences could exist in different regions of each country.

Opinions on recommended or mandatory vaccinations are divided, because several ethical issues are related to the subject $[11,12]$. Furthermore, at first sight there seems to be no striking difference in vaccination coverage between countries that only recommend certain vaccinations and countries that oblige them $[1,12]$, although from studies it is known that making influenza vaccination mandatory for healthcare workers can increase the vaccination coverage rates in this particular group [13]. On the other hand, in 2008 the Veneto region in Italy, with a population of five million, abolished all mandatory vaccination, and the coverage trend was carefully monitored. A vaccine coverage evaluation, performed in the region during 2010 for the 2008 birth cohort (the first cohort concerned by the change), revealed a slight decline of immunisation coverage rates for all the vaccinations mandatory prior to 2008 (diphtheria, hepatitis B, polio, tetanus) though levels remain well above the objective of $95 \%$, 
TABLE 1

Modality of implementation of childhood vaccination programme by country, the European Union countries, Iceland and Norway, $2010(n=29)^{*}$

\begin{tabular}{|c|c|c|c|c|c|c|c|}
\hline $\begin{array}{l}\text { A } \\
\text { Country }\end{array}$ & Diphtheria & $\begin{array}{c}\text { Haemophilus } \\
\text { influenzae type B }\end{array}$ & Hepatitis A & $\begin{array}{l}\text { Hepatitis } \\
\text { B }\end{array}$ & $\begin{array}{c}\text { Human } \\
\text { papillomavirus }^{a}\end{array}$ & Influenza & $\begin{array}{l}\text { Invasive disease } \\
\text { caused by Neisseria } \\
\text { meningitides group C }\end{array}$ \\
\hline Austria & RA & RA & $\mathrm{RR}$ & RA & $\mathrm{R}$ & $\mathrm{RR}$ & RA \\
\hline Belgium & RA & RA & $\mathrm{RR}$ & $\left.\mathrm{MR} / \mathrm{RA}^{\mathrm{b}}\right)$ & $\mathrm{R}$ & $\mathrm{RR}$ & RA \\
\hline Bulgaria & MA & MA & $\mathrm{RR}$ & MA & $\mathrm{R}$ & $\mathrm{RR}$ & A \\
\hline Cyprus & RA & RA & RR & RA & A & RR & RA \\
\hline Czech Republic & MA & MA & MR & MA & $\mathrm{R}$ & $\mathrm{RR}$ & RR \\
\hline Denmark & RA & RA & RR & RR & $\mathrm{R}$ & RR & RR \\
\hline Estonia [6] & RA & RA & $\mathrm{RA}^{\mathrm{e}}$ & RA & $\mathrm{R}^{\mathrm{e}}$ & $\mathrm{RA}^{\mathrm{e}}$ & $\mathrm{RR}^{\mathrm{e}}$ \\
\hline Finland & RA & RA & $\mathrm{RR}$ & $\mathrm{RR}$ & A & RA & A \\
\hline France & $M A / M R / R A^{f}$ & RA & RR & $\mathrm{MR} / \mathrm{RA}^{\mathrm{b}}$ & $\mathrm{R}$ & RR & RA \\
\hline Germany [7] & RA & RA & $\mathrm{RR}$ & RA & $\mathrm{R}$ & $\mathrm{RR}$ & RA \\
\hline Greece & MA & RA & RA & $M A^{h}$ & $\mathrm{R}$ & $\mathrm{RR}$ & RA \\
\hline Hungary & MA & MA & MR & MA & A & RR & A \\
\hline Iceland & RA & RA & RR & RR & A & $\mathrm{RR}$ & RA \\
\hline Ireland & RA & RA & RR & RA & $\mathrm{R}$ & RR & RA \\
\hline Italy & $M^{i}$ & RA & $A^{\prime}$ & MA & $\mathrm{R}$ & RR & $\mathrm{RA} / \mathrm{RR}^{\mathrm{k}}$ \\
\hline Latvia & RA & RA & RR & RA & RA & $\mathrm{RR}$ & RR \\
\hline Lithuania & RA & RA & RR & RA & A & RR & RR \\
\hline Luxembourg [8] & RA & RA & $\mathrm{RR}$ & RA & $\mathrm{R}$ & $\mathrm{RR}$ & RA \\
\hline Malta & MA & RA & RR & RA & A & RA & A \\
\hline The Netherlands [9] & RA & RA & RR & RR & $\mathrm{R}$ & RR & RA \\
\hline Norway & RA & RA & A & RR & $\mathrm{R}$ & RR & A \\
\hline Poland & MA & MA & RR & MA & $\mathrm{R}$ & RR & RR \\
\hline Portugal & $\mathrm{RA} / \mathrm{MR}$ & RA & A & RA & $\mathrm{R}$ & RR & RA \\
\hline Romania & MA & MA & $\mathrm{RR}$ & MA & $\mathrm{R}$ & $\mathrm{RR}$ & A \\
\hline Slovakia & MA & MA & $M R / R^{p}$ & MA & $\mathrm{R}$ & $\mathrm{MR} / \mathrm{RR}^{\circ}$ & RR \\
\hline Slovenia & MA & MA & RR & MA & $\mathrm{R}$ & RR & RR \\
\hline Spain & RA & RA & $\mathrm{RR} / \mathrm{RA}^{\mathrm{k}}$ & RA & $\mathrm{R}$ & $\mathrm{RR}$ & RA \\
\hline Sweden & RA & RA & A & $\mathrm{RR}$ & $R$ & $\mathrm{RR}$ & A \\
\hline United Kingdom & RA & RA & RR & $\mathrm{RR}$ & $\mathrm{R}$ & $\mathrm{RR}$ & RA \\
\hline
\end{tabular}

A: absence of recommendation, MA: mandatory for all; MR: mandatory for people at risk; R: recommended; RA: recommended for all; RR: recommended for people at risk.

b Mandatory for healthcare workers.

d RA: conjugated vaccine to children younger than two years of age.

RR: polysaccharide vaccine to older persons.

e Not included in the national immunisation programme, but recommended by the Ministry of Social Affairs [10].

f MA: children up to 18 months of age.

MR: healthcare workers.

RA: bolder than 13 years of age.

$\mathrm{g}$ MA: children up to 13 years of age.

MR: healthcare workers.

RA: older than 13 years of age.

h No penalty exists for non-compliance.

j One of 20 regions does not have any mandatory vaccination as of 2008 .

k Regional variability.

m Rubella: mandatory for girls by the age of 14 . 
TABLE 1

Modality of implementation of childhood vaccination programme by country, the European Union countries, Iceland and Norway, $2010(\mathrm{n}=29)^{*}$

\begin{tabular}{|c|c|c|c|c|c|c|c|c|}
\hline $\begin{array}{l}\text { B } \\
\text { Country }\end{array}$ & $\begin{array}{c}\text { Invasive } \\
\text { pneumococcal } \\
\text { disease }\end{array}$ & $\begin{array}{l}\text { Measles- } \\
\text { mumps- } \\
\text { rubella }\end{array}$ & Pertussis & Polio & Rotavirus & Tetanus & $\begin{array}{c}\text { Tuberculosis } \\
\text { (with Bacillus } \\
\text { Calmette-Guérin ) }\end{array}$ & Varicella \\
\hline Austria & RA & RA & RA & RA & RA & RA & A & RR \\
\hline Belgium & RA & RA & RA & MA & RA & RA & $A$ & RR \\
\hline Bulgaria & $\mathrm{MA} / \mathrm{RA}^{\mathrm{c}}$ & MA & MA & MA & RA & MA & MA & A \\
\hline Cyprus & RA & RA & RA & RA & A & RA & $\mathrm{RR}$ & $\mathrm{RA} / \mathrm{RR}$ \\
\hline Czech Republic & MR & MA & MA & MA & $A$ & MA & MR & $\mathrm{RR}$ \\
\hline Denmark & $\mathrm{RA} / \mathrm{RR}^{\mathrm{d}}$ & RA & RA & RA & $A$ & RA & $A$ & RR \\
\hline Estonia [6] & $\mathrm{RR}^{\mathrm{e}}$ & RA & RA & RA & $\mathrm{RR}^{\mathrm{e}}$ & RA & RA & $\mathrm{RR}^{\mathrm{e}}$ \\
\hline Finland & RA & RA & RA & RA & RA & RA & RR & $A$ \\
\hline France & RA & RA & RA & $\mathrm{MA} / \mathrm{MR} / \mathrm{RA}^{\mathrm{g}}$ & $A$ & $M A / M R / R A^{f}$ & $M R / R^{b}$ & RR \\
\hline Germany [7] & RA & RA & RA & RA & A & RA & A & RA \\
\hline Greece & RA & RA & RA & $M A^{h}$ & $A$ & MA & RA & RA \\
\hline Hungary & RA & MA & MA & MA & A & MA & MA & A \\
\hline Iceland & $\mathrm{RR} / \mathrm{RA}^{\mathrm{i}}$ & RA & RA & RA & $A$ & RA & $A$ & RR \\
\hline Ireland & RA & RA & RA & RA & $A$ & RA & RA & RR \\
\hline Italy & $\mathrm{RA} / \mathrm{RR}^{\mathrm{k}}$ & RA & RA & MA & $A$ & MA & $\mathrm{RR}$ & $\mathrm{RA} / \mathrm{RR}^{\mathrm{k}}$ \\
\hline Latvia & RA & RA & RA & RA & RA & RA & RA & RA \\
\hline Lithuania & $\mathrm{RR}$ & RA & RA & RA & $A$ & RA & RA & $\mathrm{RR}$ \\
\hline Luxembourg [8] & RA & RA & RA & RA & RA & RA & $\mathrm{RR}$ & RA \\
\hline Malta & $\mathrm{RR}^{\mathrm{n}}$ & $\mathrm{RA}^{\mathrm{m}}$ & RA & MA & A & MA & RA & RR \\
\hline The Netherlands [9] & RA & RA & RA & RA & A & RA & $\mathrm{RR}$ & A \\
\hline Norway & RA & RA & RA & RA & $A$ & RA & $\mathrm{RR}$ & $A$ \\
\hline Poland & MR & $M A$ & MA & MA & RA & MA & MA & $\mathrm{RR}$ \\
\hline Portugal & $\mathrm{RR}$ & RA & RA & RA & $A$ & $\mathrm{RA} / \mathrm{MR}$ & RA & $A$ \\
\hline Romania & $A$ & MA & MA & MA & $A$ & MA & MA & $A$ \\
\hline Slovakia & MA & MA & $\mathrm{MA}$ & MA & $A$ & MA & MA & A \\
\hline Slovenia & $\mathrm{RR}$ & MA & MA & MA & RA & MA & $\mathrm{RR}$ & RR \\
\hline Spain & $\mathrm{RA} / \mathrm{RR}^{\mathrm{k}}$ & RA & RA & RA & A & RA & $A^{\prime}$ & $\mathrm{RA} / \mathrm{RR}^{\mathrm{k}}$ \\
\hline Sweden & RA & RA & RA & RA & $A$ & RA & $\mathrm{RR}$ & A \\
\hline United Kingdom & RA & RA & RA & RA & A & RA & $\mathrm{RR}$ & $\mathrm{RR}$ \\
\hline
\end{tabular}

A: absence of recommendation, MA: mandatory for all; MR: mandatory for people at risk; R: recommended; RA: recommended for all; $R R$ : recommended for people at risk.

a Mostly recommended for girls 10-17 years of age.

b Mandatory for healthcare workers.

c RA: children born prior to 2010 and younger than five years of age.

d RA: conjugated vaccine to children younger than two years of age.

RR: polysaccharide vaccine to older persons.

e Not included in the national immunisation programme, but recommended by the Ministry of Social Affairs [10].

RA: from 2011.

k Regional variability.

RA: only in one region.

RR: for children under two years of age.

- MR: social care facilities.

RR: children six months to 12 years of age, elderly, for some diagnoses, for some professions.

p MR: direct contact with infectious person, some professions.

RR: chronic liver disease, children two years of age living in bad conditions, some professions. 
TABLE 2

Modality of implementation of childhood vaccination programme by vaccine in the European Union countries, Iceland and Norway, 2010*

\begin{tabular}{|c|c|c|c|c|}
\hline Vaccination & $\begin{array}{l}\text { Considering } \\
\text { vaccination }\end{array}$ & $\begin{array}{l}\text { Recommended } \\
\text { (RA or RR) }\end{array}$ & $\begin{array}{c}\text { Mandatory (MA } \\
\text { or MR) }\end{array}$ & Mixed \\
\hline Diphtheria & 29 & 17 & 10 & 2 \\
\hline Haemophilus influenzae type B & 29 & 22 & 7 & 0 \\
\hline Hepatitis A & 25 & 23 & 1 & 1 \\
\hline Hepatitis B & 29 & 18 & 9 & 2 \\
\hline Human papillomavirus & 23 & 23 & NM & 0 \\
\hline Influenza & 29 & 28 & NM & 1 \\
\hline Invasive disease caused by Neisseria meningitides serogroup C & 22 & 22 & NM & 0 \\
\hline Invasive pneumococcal disease & 28 & 24 & 3 & 1 \\
\hline Measles-mumps-rubella & 29 & 22 & 7 & 0 \\
\hline Polio & 29 & 17 & 11 & 1 \\
\hline Pertussis & 29 & 22 & 7 & 0 \\
\hline Rotavirus & 9 & 9 & NM & 0 \\
\hline Tetanus & 29 & 17 & 10 & 2 \\
\hline Tuberculosis (with Bacillus Calmette-Guérin) & 23 & 16 & 6 & 1 \\
\hline Varicella & 20 & 20 & NM & 0 \\
\hline
\end{tabular}

MA: mandatory for all; MR: mandatory for people at risk; NM: not mandatory in any of the countries in the study; RA: recommended for all; RR: recommended for people at risk.

as aimed for by the Italian National Immunisation Plan [14]. The evaluation of this experience, over time, may lead to legislative changes at national level [15]. Further research and reports of experiences are needed to see if a relation exists between voluntary or mandatory vaccination programmes, and vaccination coverage.

In countries where both recommended and mandatory vaccinations are part of the national immunisation plan (i.e. France, Greece, Italy, Malta) vaccines against pertussis, measles-containing vaccines and vaccines against Hib are recommended, not mandatory, and the coverage is still very high [16]. Thus the label 'mandatory' is not the only driver behind achieving a high vaccination coverage in these countries and many other factors can play a role such as the use of combined vaccines, prices for the recipient, kind of offer, information and promotional campaigns. The results of our survey show that there are several differences among participating countries. Immunisation strategies range from only voluntary vaccinations in the programme to an almost completely mandatory vaccination programme, and everything in between. The reasons behind such wide differences are probably both historical and cultural rather than evidence-based. Differences in costs for recipients and the kind of vaccination offer, whether active or passive, also exist. These aspects have been explored through other, disease-specific, surveys performed by VENICE [4].
The issue of mandatory versus recommended vaccinations has been widely discussed in Europe. The situation might change over the coming years following the example of countries where high coverage is achieved, taking advantage of communication strategies and the awareness of the citizen for public health problems and relative solutions.

In conclusion, a national healthcare system should promote and actively offer those vaccines that have been proven to be safe, effective, and with a positive public health impact. In a world where people trust health authorities, more compliance with national recommendations can be established. This would not only benefit the health of citizens, but also support the overall effectiveness of a vaccination programme through the herd immunity effect.

However, communication of the risks and of advantages and disadvantages resulting from large immunisation programmes is a very sensitive issue and any decision about a proposal for vaccine strategies should be elaborated in agreement with tradition and cultural habits.

In this quick survey a recommended vaccination was considered to be a "vaccine included in the national immunisation plan but not mandatory'. Some countries may not have a unique official document for recommended vaccinations and therefore it may not be straightforward to categorise a vaccine as recommended or not. A different use of the term 'recommended' could also 
explain some differences to the programme reported on the World Health Organization website [17].

Meanwhile more information about the diversity in vaccine offer at European level may help countries to adapt vaccination strategies based on the experience of other countries. In this way it is possible also to improve the vaccine offer to the citizen and to increase the awareness of European citizens about the importance of vaccination for public health and the underlying evidence for the strategies chosen. The availability of comparable vaccination coverage data for all the Member States will help this process.

\section{* Authors' correction}

The modalities of implementation of the childhood vaccination programme for Latvia were corrected in Tables 1 and 2 . The affected numbers in the text were also corrected accordingly. These corrections were made on 3 July 2019, upon request of the authors.

\section{The VENICE project gatekeepers group:}

Austria: Jean-Paul Klein. Belgium: Martine Sabbe, Pierre Van Damme. Bulgaria: Mira Kojouharova. Cyprus: Soteroulla Soteriou, Chrystalla Hadjianastassiou. Czech Republic: Bohumir Kriz. Denmark: Steffen Glismann. Estonia: Natalia Kerbo, Irina Filippova. Finland: Tuija Leino. France: Daniel Levy-Bruhl. Germany: Sabine Reiter. Greece: Theodora Stavrou. Hungary: Zsuzsanna Molnàr. Iceland: Thorolfur Gudnason. Ireland: Suzanne Cotter. Italy: Fortunato D’Ancona, Maria Cristina Rota. Latvia: Jurijs Perevoscikovs. Lithuania: Egle Valikoniene. Luxemburg: Françoise Berthet. Malta: Charmaine Gauci, Tanya Melillo. The Netherlands: Hester de Melker, Alies van Lier. Norway: Berit Feiring. Poland: Pawel Stefanoff. Portugal: Teresa Fernandes, Paula Valente. Romania: Chicin Gratiana. Slovakia: Helena Hudecova, Jarmila Lancova. Slovenia: Alenka Kraigher. Spain: Josefa Masa-Calles, Isabel Pachón del Amo. Sweden: Annika Linde. United Kingdom: Richard Pebody.
7. Robert Koch Institute (RKI). Aktuelle Empfehlungen der STIKO. [Accessed: 5 Nov 2010] German. Available from: http://www.rki.de/DE/Content/Infekt/EpidBull/Archiv/2011/ Ausgaben/30_11.pdf?_blob=publicationFile.

8. Rijksinstituut voor Volksgezondheid en Milieu (RIVM). Rijksvaccinatieprogramma (RVP). Vaccinatieschema. [Accessed: 5 Nov 2010]. Dutch. Available from http://www. rivm.nl/rvp/rijks vp/vac schema/.

9. Ministère de la Santé Luxembourg. Vaccinations recommandées. [Accessed: 9 Nov 2010]. French. Available from: http://www.sante.public.lu/fr/rester-bonne-sante/ vaccinations/vaccination-recommandations/index.html.

10. Terviseamet. Estonian Health Board. [Internet]. [Vaccination recommendations] [Accessed: 5 Nov 2010] Estonian. Available from: http://www.vaktsineeri.ee/vaktsineerimissoovitused. html

11. Isaacs D, Kilham H, Leask J, Tobin B. Ethical issues in immunisation. Vaccine. 2009;27(5):615-8.

12. Salmon DA, Teret SP, Maclntyre CR, Salisbury D, Burgess MA, Halsey NA. Compulsory vaccination and conscientious or philosophical exemptions: past, present, and future. Lancet. 2006;367(9508):436-42.

13. Babcock HM, Gemeinhart N, Jones M, Dunagan WC, Woeltje KF. Mandatory influenza vaccination of healthcare workers: translating policy to practice. Clin Infect Dis. 2010;50(4):459-64

14. Veneto Region. [Report on immunization activities, birth cohorts 2008 and 2007 , and monitoring of mandatory vaccination abolition, birth cohorts 2009 and 2010]. 2011. Accessed 1 Feb 2012 [Italian]. Available from: http://www.regione.veneto.it/NR/ rdonlyres/89018626-6853-447A-868A-348EA8857EF6/o/ MonitoraggiodelsistemavaccinaledelVenetoal31marz02011.pdf

15. Molinelli A, Bonsignore A, Querci A, Icardi G, Martini M, Durando P. Towards the suspension of compulsory vaccination in Italy: balancing between public health priorities and medicolegal and juridical aspects. J Prev Med Hyg. 2009;50(3):135-40.

16. World Health Organization (WHO). Vaccine-preventable diseases: monitoring system 2011 global summary. WHOUNICEF estimates of DTP3 coverage.[Accessed: 1 Feb 2012]. Available from: http://www.who.int/immunization_monitoring/ en/globalsummary/timeseries/tswucoveragedtp3.htm

17. World Health Organization (WHO). Vaccine Preventable Diseases Monitoring System Immunization schedules by antigen, selection centre. Available from: http://apps.who.int/ immunization_monitoring/en/globalsummary/ScheduleSelect. $\mathrm{cfm}$

\section{References}

1. World Health Organization (WHO) European Region.

Centralized information system for infectious diseases (CISID).

[Accessed: 9 Nov 2010]. Available from: http://data.euro.who. int $/$ cisid $/$ ?TabID $=67$.

2. Muscat M, Bang H, Wohlfahrt J, Glismann S, Mølbak K; EUVAC. NET Group. Measles in Europe: an epidemiological assessment. Lancet. 2009. 373(9661):383-9.

3. Vaccine European New Integrated Collaboration Effort (VENICE). Report on First survey of Immunisation Programs in Europe. 2007. Available from: http://venice.cineca.org/ Report_II_WP3.pdf

4. Vaccine European New Integrated Collaboration Effort [Internet]. Vaccine European New Integrated Collaboration Effort. (VENICE). Nov 2010. Available from: http://venice. cineca.org/

5. King, LA, Lévy-Bruhl D, O’Flanagan D, Bacci S, Lopalco PL, Kudjawu Y, et al. Introduction of human papillomavirus (HPV) vaccination into national immunisation schedules in Europe: Results of the VENICE 2007 survey. Euro Surveill. 2008;13(33). Available from: http://www.eurosurveillance.org/ViewArticle. aspx?Articleld $=18954$

6. Terviseamet. Estonian Health Board. [Internet]. [The national immunisation programme]. [Accessed: 2 Jan 2012]. Estonian. Available from: http://vaktsineeri.ee/riiklikimmuniseerimiskava.html 